\title{
Evaluation of the friction properties of thermally sprayed coatings
}

\author{
M. Kašparová, F. Zahálka \& Š. Houdková \\ Department of Thermal Spraying, ŠKODA VÝZKUM Ltd., \\ Czech Republic
}

\begin{abstract}
In this paper, one of the tribological tests for the evaluation of friction properties is introduced. The test, named "Block-on-Ring", (in accordance with the standard ASTM G77) was carried out by the ŠKODA VÝZKUM Ltd. company and realized on renovated apparatus. The brief description of the measurement is as follows: the flat surface of the sample is pressed against the cylindrical surface of the rotating wheel. Arbitrary oil is fed to the materials' contact surface and the increasing temperature can be detected using the thermocouple that is placed in close proximity of the contact materials. Using the strain-gauge dynamometer, the friction force is recorded. The test is run on a number of periods and, including after the first expiration time, the wear track formed in the sample is measured and evaluated. The final results are the summary of partial results of the long-standing tests, which serve for the preliminary detection of the friction behaviour of the materials. The friction properties of the thermally sprayed coatings were investigated. The $\mathrm{Cr}_{3} \mathrm{C}_{2}-\mathrm{NiCr}, 13 \% \mathrm{Cr}$ and $\mathrm{Cr}_{2} \mathrm{O}_{3}$ coatings were tested. The thin-base babbit was selected as the counter-part. The main interest was in the characterization of the friction properties in the dependence on the amount of added lubricant and on the normal load of sliding couples.
\end{abstract}

Keywords: friction, block-on-ring, thermally sprayed coatings.

\section{Introduction}

Friction properties rank among many important material properties which characterize the tribological behaviour of materials that are in a sliding contact. Because of the sliding between two or more machine parts friction arises. Friction is the resistance to motion during sliding or rolling that occurs when one 
solid body moves tangentially over another one with which it is in contact. Then the resistive tangential force, which acts in a direction directly opposite to the direction of motion, is called the friction force. There are two main types of friction: dry friction and fluid friction. If the solid bodies are loaded together and a tangential force is applied, the value of the tangential force that is required to initiate the motion is the static friction force. It may take a few milliseconds before the relative motion is initiated at the interface. The tangential force required to maintain the relative motion is known as the kinetic or dynamic friction force. The static friction force is higher than the kinetic friction force, as Bhushan [1] showed. The science called "tribology" deals with main friction problems. A wide part of tribology science solves the following questions: surfaces interface, adhesive wear and lubrication of machine units. It is evident that in addition to the friction, wear also occurs. Vocel et al. [2] mentioned that friction without wear may occur if the hydrodynamic lubrication of function surfaces occurs and the compact lubricant layer is spread between two contact bodies. Friction and friction characteristics are advantageously measured using laboratory tribo-tests. The complete tests are described in the related Standards. The "Block-on-ring" test specified in the ASTM G77 [3] was used for determination of the friction properties of several selected thermally sprayed coatings $\left(\mathrm{Cr}_{3} \mathrm{C}_{2}-\mathrm{NiCr}\right.$ cermet, $\mathrm{Cr}_{2} \mathrm{O}_{3}$ ceramic and $13 \% \mathrm{Cr}$ stainless steel).

\section{Experimental}

\section{1 "Block-on-ring" method}

In ŠKODA VÝZKUM Ltd., the friction properties are evaluated using the "Block-on-Ring" apparatus, see fig.1b. The test is generally characterized in such a way that the flat surface of the sample (block) is pressed against the cylindrical surface of the rotating wheel of the rotors material (ring). Arbitrary oil is fed to the material contact surface and increasing temperature is detected using the thermocouple. The thermocouple is placed in the hole in the block sample. The hole is drilled $1 \mathrm{~mm}$ under the surface, in other words $1 \mathrm{~mm}$ under the samples contact, see Fig.2. The friction force is recorded using the straingauge dynamometer. A schematic draft of the test principle is depicted in Fig.1a. The test runs in a number of periods and always after one expiration time the wear track formed in the block-sample is measured and evaluated. One of the disadvantages of this apparatus is the constant velocity of the ring sample. Because of this, it is impossible to change the speed of the ring rotation and to record the statical coefficient of friction.

Using this apparatus it is possible to measure a dynamic friction coefficient in lubricated conditions, thermal changes in the materials contact, wear coefficient, the actual load of a sliding couple in the contact surfaces and it is possible to monitor the waveform of the friction force during the test running. The equations for determination these characteristic quantities are stated in $[4,9,10]$.

For the experiment the nominal load of $1 \mathrm{MPa}, 2,5 \mathrm{MPa}$ and 3,5 $\mathrm{MPa}$ and sliding distance of $500 \mathrm{~km}$ was used. The total distance was divided in six 
cycles. The first cycle was the running-up step and it's length was one kilometre. Each for further five steps was one-hundred kilometres long. The determination of the volume loss of the block sample is stated in ASTM G77 [3]. The scar width was measured by the magnifying glass with accuracy of measurement of $0,1 \mathrm{~mm}$.

\subsection{Experimental materials}

Three samples of thermally sprayed coatings were chosen for the experimental measurement: one kind of cermet coating on the base of $\mathrm{Cr}_{3} \mathrm{C}_{2}$-carbide sprayed using "high-velocity-oxygen-fuel system" (HVOF), 13\% $\mathrm{Cr}$ stainless steel sprayed using electric arc spray technology and ceramic coating of $\mathrm{Cr}_{2} \mathrm{O}_{3}$ sprayed using plasma spray technology.

The $\mathrm{Cr}_{3} \mathrm{C}_{2}-\mathrm{NiCr}$ coatings are commonly used as a protector against different types of wear up to approx. $850^{\circ} \mathrm{C}$. Their superior oxidation resistance has seen them applied in a range of applications subject to combined erosion and high

a)

b)
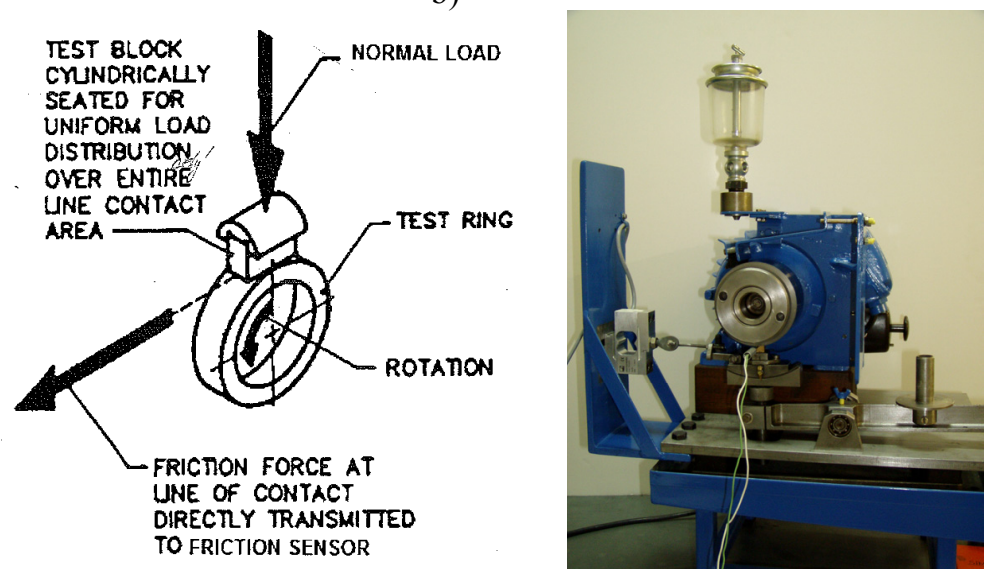

Figure 1: a) Test schematic - principle of the measuring of friction [3], b) "Block-on-ring" apparatus.

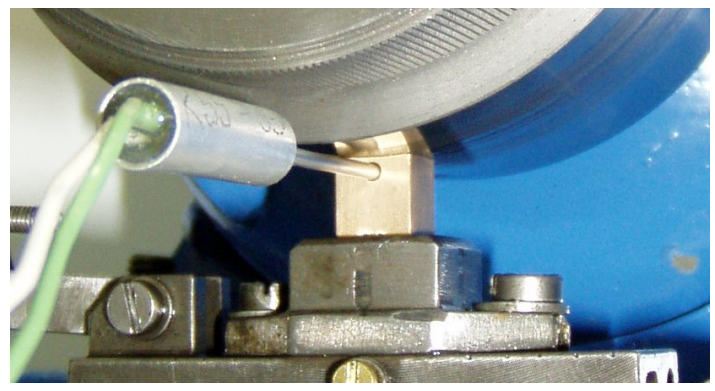

Figure 2: $\quad$ Temperature detection. 
temperature corrosion [4], for example for turbine compression rings, jet engine components, replacing of hard chromium plating and so on. The coatings of $13 \% \mathrm{Cr}$ stainless steel are sprayed on such surfaces where relatively good resistance of abrasion, corrosion and high-temperature oxidation is required. They are advantageously used for the pistons, headless bushings, bearing pins, etc. Plasma sprayed ceramic coatings have excellent performance in resisting high temperature, wear, corrosion and erosion. The $\mathrm{Cr}_{2} \mathrm{O}_{3}$ coating has good resistance in chemical environments and high resistance against the mechanical stress with low coefficient of friction. The ceramic coatings on the base of $\mathrm{Cr}_{2} \mathrm{O}_{3}$ are widely used as sealing parts of energetic, chemical and industrial machines. The surface hardness of tested coatings is mentioned in Table 1. The resultant values are the average values of three measurements.

The coatings were sprayed in ŠKODA VÝZKUM Ltd., Pilsen, CZ, only the plasma spraying was performed in Plasmametal, CZ. The used spray parameters are the intellectual property of the companies. The coatings were deposited on the test ring pieces of EN 10025-90 low-carbon steel.

The "stanit" tin-based babbit was chosen as the block sample. The "Stanit" tin-based babbit is one of many kinds of tin-compositions on the base of Sn-Sb$\mathrm{Cu}$. Its chemical composition is given in Table 2. The copper is very important additive for this alloy. $\mathrm{Cu}$ with $\mathrm{Sn}$ creates the chemical compound of $\mathrm{Cu}_{6} \mathrm{Sn}_{5}$ that crystallizes during cooling as first and it creates the dendritic skeleton. On the skeleton the crystals of the $\mathrm{SnSb}$ begin to grow [5]. Using the copper the crystals of $\mathrm{SnSb}$ are kept in the liquid by $\mathrm{Cu}_{6} \mathrm{Sn}_{5}$ that prevents to crystals segregation. Due to the copper the crystals of $\mathrm{SnSb}$ are after the crystallization homogenously distributed in whole structure. The $\mathrm{SnSb}$ together with $\mathrm{Cu}_{6} \mathrm{Sn}_{5}$ then creates the skeleton of the bearing [6-8].

\subsection{Lubrication}

The "Block-on-Ring" method facilitates to use many kinds of lubricants in a fluid stage. The lubricants, mostly oils, are injected into the surface contact of the samples. Oils include natural organics consisting of animal fat, vegetable oils, mineral fractions, synthetic organics and mixtures of two or more of these materials. It is mentioned in [1] that the main aim of the lubricants is the decreasing in friction losses, wear, noise level, and increase in absorbing and corrosive resistance. Currently in the industrial market many types of liquid

Table 1: Coating macro-hardness (HRC).

\begin{tabular}{|c|c|c|}
\hline $\mathrm{Cr}_{3} \mathrm{C}_{2}-\mathrm{NiCr}$ & $\mathrm{Cr}_{2} \mathrm{O}_{3}$ & $13 \% \mathrm{Cr}$ \\
\hline $61.8 \pm 2.3$ & $68 \pm 3.1$ & $32 \pm 1.8$ \\
\hline
\end{tabular}

Table 2: Chemical composition of the "stanit" tin-based babbit.

\begin{tabular}{|c|c|c|c|c|c|}
\hline \multirow{3}{*}{ Stanit } & $\mathrm{Sb} \mathrm{( \% )}$ & $\mathrm{Cu}(\%)$ & $\mathrm{Ni}(\%)$ & $\mathrm{Pb} \mathrm{( \% )}$ & $\mathrm{Sn}(\%)$ \\
\cline { 2 - 6 } & $9-11$ & $2-4$ & $0.4-1.0$ & $\max .1$ & $84.5-86.5+0.5-1.1 \mathrm{Cd}$ \\
\hline
\end{tabular}


lubricants are offered. From this large offering it is necessary to select the suitable lubricant for the practical application where moving parts with a sliding contact will work. The main tribological components in practical applications are for example, bearings, seals, cams, piston rings, electrical brushes, cutting and forming tools, etc. For the experiment the turbine deeply refined TSA 32 oil (in accordance with the ISO 6743 Standard) was chosen. This oil is characterized by the outstanding oxidative stability and antirust performance to protect turbines from rust and corrosion in severe conditions. It is suitable for steam turbines and water turbines, pumps and valves. The viscosity of the lubricant at temperature $40^{\circ} \mathrm{C}$ is $28,8-35,2 \mathrm{~mm}^{2} / \mathrm{sec}$. The thermal stability and its using are possible up to temperature $140^{\circ} \mathrm{C}$. During the experiments the lubricant supply to the sliding contact was changed. The amount of lubricant was at all times sufficient for "the mixed friction." The test parameters are listed in Table 3.

\subsection{Surface quality}

Tribological characteristics depend on the surface quality of the sliding components, which are in relative contact (motion). Therefore, the surface roughness of the sliding parts is very distinctive factor. The "flat" surface shows lower opposition to the sliding then the "rough" surface and the friction force is naturally lower. Due to lower friction force the wear rate of the stanit is decreasing. If the comparing tests between several different materials are required it is preferable to compare sliding couples of the same surface roughness. The surface roughness was measured using SJ-201P Surftester and the Ra parameter was measured. The results are summarized in Table 4. The resultant values are the average values of five measurements.

\section{Results of the measurements}

The waveforms of the friction force and the temperature are the primary results of the friction test. By means of the Labview software the waveforms are displayed on the screen of the laboratory PC. The measurements values are saved to the Excel program simultaneously. Because of the values saving it is possible to calculate the average values of the friction force. The average friction force

Table 3: $\quad$ Parameters of measurements.

\begin{tabular}{|c|c|c|c|}
\hline Test & 1 & 2 & 3 \\
\hline Load $[\mathrm{MPa}]$ & 1 & 2.5 & 3.5 \\
\hline Lubricant $\left[\mathrm{dm}^{3} / \mathrm{h}\right]$ & 0.018725 & 0.018725 & 0.002675 \\
\hline
\end{tabular}

Table 4: $\quad$ Surface roughness of the samples.

\begin{tabular}{|c|c|c|c|c|}
\hline Material & $\mathrm{Cr}_{3} \mathrm{C}_{2}-\mathrm{NiCr}$ & $13 \% \mathrm{Cr}$ & $\mathrm{Cr}_{2} \mathrm{O}_{3}$ & Stanit \\
\hline \multirow{2}{*}{$\mathrm{Ra}[\mu \mathrm{m}]$} & $1.10 \mathrm{E}-$ & $2.84 \mathrm{E}-$ & $1.2 \mathrm{E}-$ & $3.20 \mathrm{E}-$ \\
& $01 \pm 1.55 \mathrm{E}-02$ & $01 \pm 2.07 \mathrm{E}-02$ & $01 \pm 1.05 \mathrm{E}-02$ & $01 \pm 5.00 \mathrm{E}-02$ \\
\hline
\end{tabular}


was calculated in each of the test step and the average values were recorded. The coefficient of friction was calculated and the results are recorded in the graphs, see Fig.3-5. In the following graphs the influence of the friction coefficient on the sliding distance is recorded. Figure 3 shows the dependence of the coefficient of friction on the sliding distance under the load of $1 \mathrm{MPa}$ and amount of lubricant of $0,018725 \mathrm{dm}^{3} / \mathrm{h}$ and the Fig.4 under the load of $2.5 \mathrm{MPa}$ and amount of lubricant of $0.018725 \mathrm{dm}^{3} / \mathrm{h}$. Figure 5 shows the friction properties under the load of $3.5 \mathrm{MPa}$ and of under reduced amount of lubricant of $0.002675 \mathrm{dm}^{3} / \mathrm{h}$. For the reduced amount of lubricant the sliding distance was shortened up to 100 $\mathrm{km}$ to prevent the seizure.

It is evident that the coefficient of friction changes with the dependence on the type of coating. The fluctuation in the friction values conforms to the materials specific properties (hardness, roughness, porosity, phases

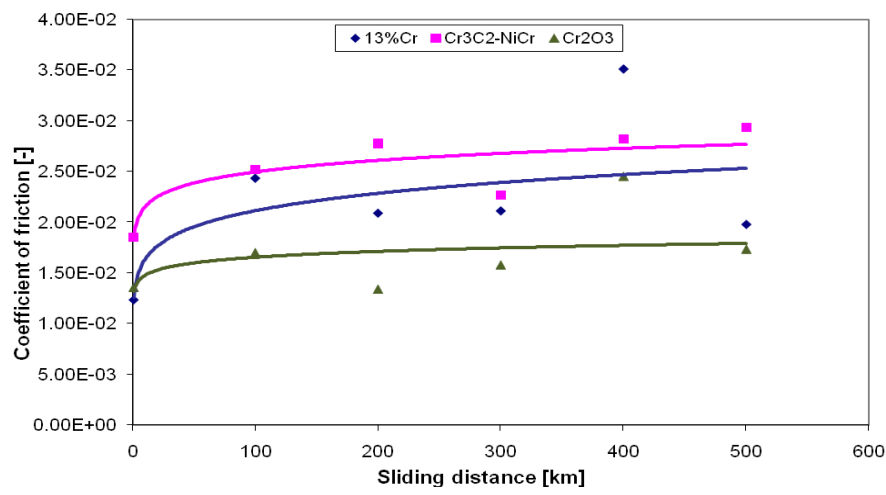

Figure 3: Dependence of the coefficient of friction on the sliding distance, load of $1 \mathrm{MPa}$, lubricant of $0.018725 \mathrm{dm}^{3} / \mathrm{h}$.

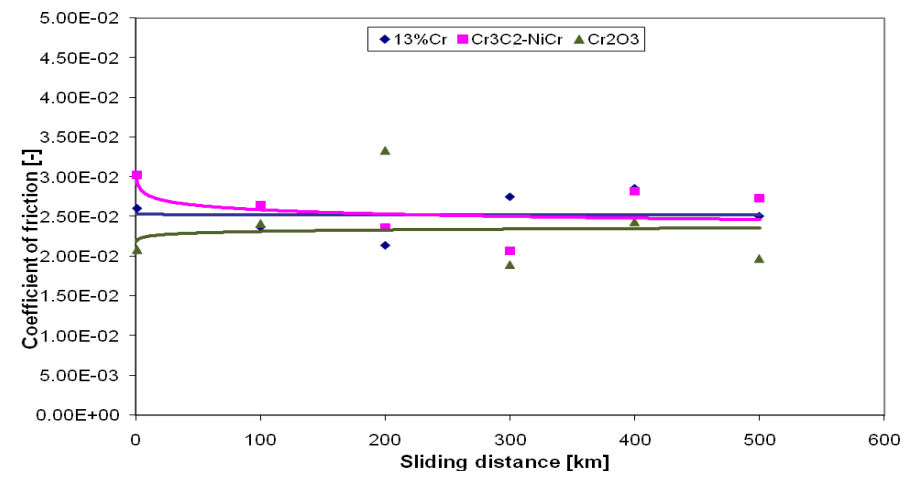

Figure 4: Dependence of the coefficient of friction on the sliding distance, load of $2.5 \mathrm{MPa}$, lubricant of $0.018725 \mathrm{dm}^{3} / \mathrm{h}$. 


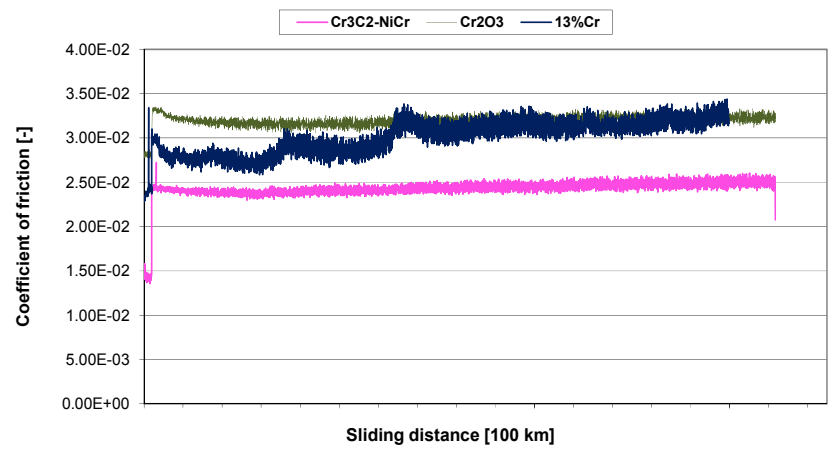

Figure 5: Dependence of the coefficient of friction on the sliding distance, load of $3.5 \mathrm{MPa}$, lubricant of $0.002675 \mathrm{dm}^{3} / \mathrm{h}$.

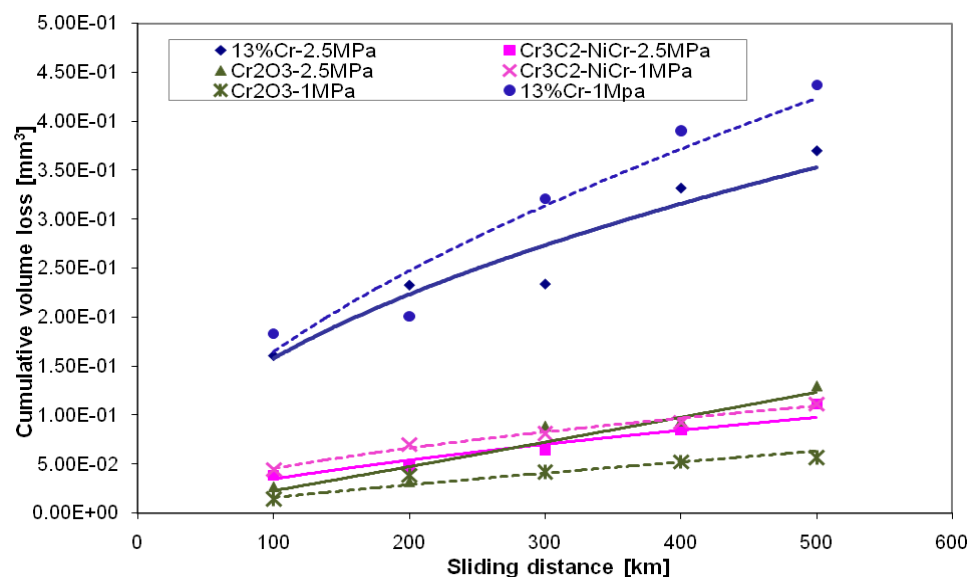

Figure 6: Wear of the block sample - stanit during sliding under the loads of $1 \mathrm{MPa}$ and $2.5 \mathrm{MPa}$.

composition). The graphical dependencies show that the difference between the friction coefficients is not so significant. The difference between individual sliding couples is only about the value of 0.01 . During sliding under the load of 1 $\mathrm{MPa}$, Fig.3, the friction coefficient rises during the first $100 \mathrm{~km}$ of run and stabilises for all coatings after covering of $100 \mathrm{~km}$. However, it is evident that increasing of the normal load leads to the stabilizing of the friction coefficient on the uniform value that is identical for all tested coatings (0.025), see Fig.4.

During sliding, the wear of the softer component of the sliding couple is generated. In our case the softer element is the block sample - stanit. The cumulative volume loss of the stanit is recorded in Fig. 6 and 7. In Fig. 6 the wear of the stanit under the load of $1 \mathrm{MPa}$ and of $2.5 \mathrm{MPa}$ and in Fig. 7 the wear 


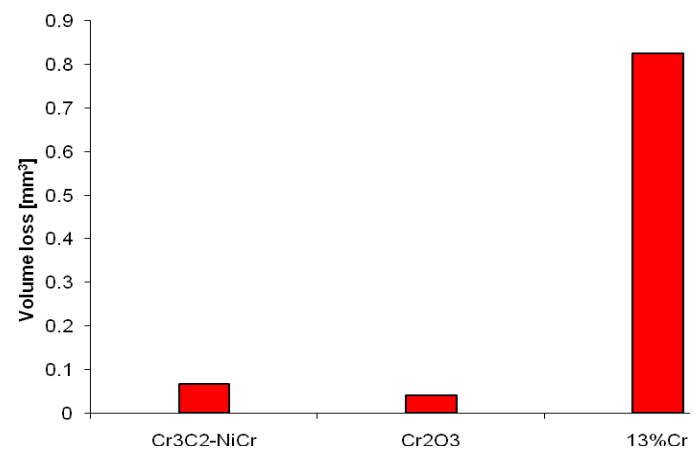

Figure 7: Wear of the block sample - stanit during sliding under the load of $3.5 \mathrm{MPa}(100 \mathrm{~km})$.

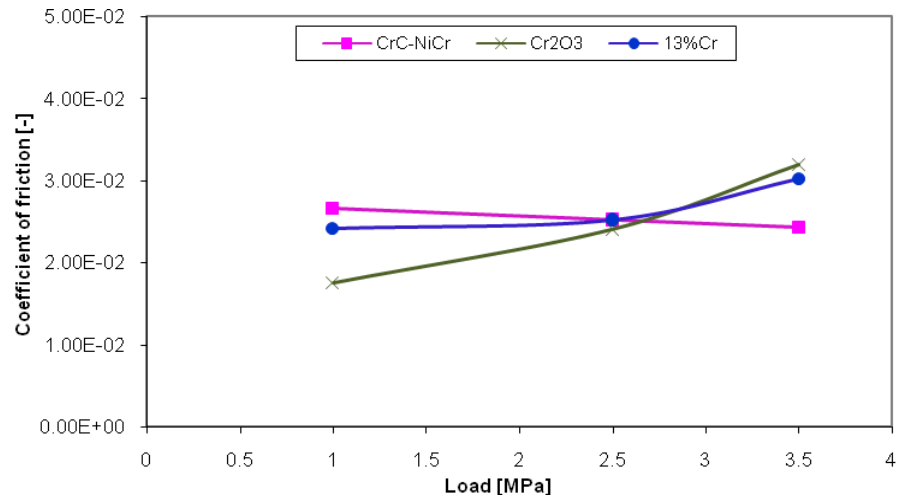

Figure 8: The dependence of the friction coefficient on the normal load.

of stanit under the load of $3.5 \mathrm{MPa}$ is recorded. It is evident that the volume loss of the stanit blocks doesn't change with the load change, Fig.6. The wear of the stanit uniformly increases in all tests. However, the coating of the $13 \% \mathrm{Cr}$ stainless steel causes the most extensive wear of the stanit. In the test conditions of reduced supply of lubricant and higher load even eightfold rise of the stanits wear has been occurred, see Fig.7, whereas, the volume losses of the stanit which were caused by the $\mathrm{Cr}_{2} \mathrm{O}_{3}$ ceramic and $\mathrm{Cr}_{3} \mathrm{C}_{2}-\mathrm{NiCr}$ hardmetal were nearly identical.

\section{Discussion}

The coefficient of friction is given by the ration of the friction and the normal force. The coefficient of friction in the dependence on the load differs for individual sliding couples only in narrow range of values, see Fig.8. The slight values variation can be caused by the measurement error of the strain-gauge 
dynamometer. From the results it can be said that the coefficient of friction keeps constant with increasing load. Higher values of friction coefficient under the load of $3.5 \mathrm{MPa}$ for $\mathrm{Cr}_{2} \mathrm{O}_{3}$ and $13 \% \mathrm{Cr}$ coatings is probably due to lower lubricant supply.

Due to the friction and the load action it comes to the abrasive and adhesive wear of the softer part - stanit. The Fig. 9 shows the dependence of the stanit wear on the normal load. For the sliding couple of $\mathrm{Cr}_{2} \mathrm{O}_{3} /$ stanit and $\mathrm{Cr}_{3} \mathrm{C}_{2}$ $\mathrm{NiCr} /$ stanit the wear of stanit-block increases with the increasing load linearly and the wear rise is very slight and uniform. The most aggressive counter-part for the stanit block is the coating of the $13 \% \mathrm{Cr}$ stainless steel. This coating caused the highest wear of the stanit, especially in the test conditions of the load of $3.5 \mathrm{MPa}$ and reduced lubricant supply. In the test conditions of the load of 1 $\mathrm{MPa}$ and $2.5 \mathrm{MPa}$ (constant lubricant supply) the wear of the stanit kept constant. Identical trend was indicated for the $\mathrm{Cr}_{3} \mathrm{C}_{2}-\mathrm{NiCr}$ coating. Using $\mathrm{C}_{3} \mathrm{O}_{2}$ ceramic coating the constant stanit wear was recorded for the test conditions of the loads 2.5 $\mathrm{MPa}$ and $3.5 \mathrm{MPa}$.

Further factor that is necessary to monitor during sliding is the temperature that is accumulated in the sliding contact. Each of the sliding couples has their specific temperature that is influenced by the load, surface quality of the interacting materials, amount of lubricant and naturally also by materials properties of the sliding elements. In Fig. 10 the temperature in the dependence on the used normal load is recorded. The sliding couple of $13 \% \mathrm{Cr} /$ stanit reaches the highest temperature during sliding and the rise of the temperature is even about $10^{\circ} \mathrm{C}$ in the test conditions of reduced lubricant supply and increased load. It is evident that for coatings $\mathrm{Cr}_{2} \mathrm{O}_{3}$ and $\mathrm{Cr}_{3} \mathrm{C}_{2}-\mathrm{NiCr}$ the temperature doesn't change so markedly. For these coatings the temperature slightly increases with increased load and reduced lubricant supply didn't influenced the slight rising of the temperature.

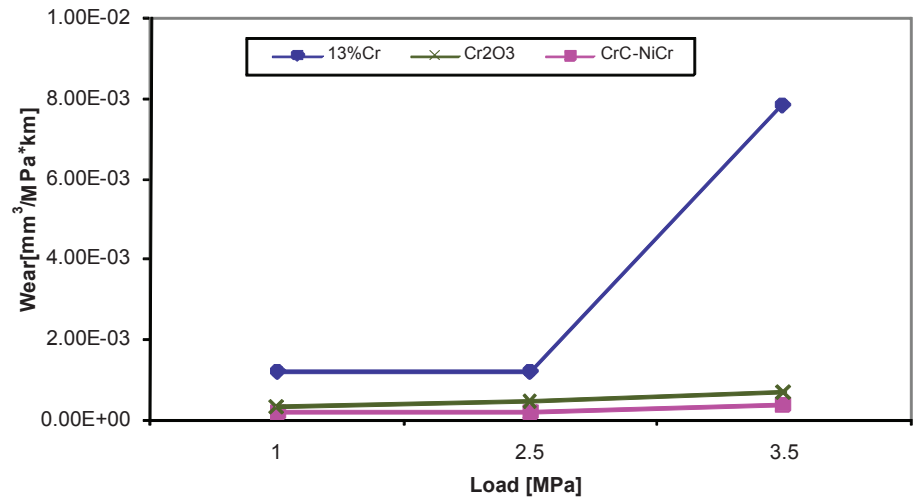

Figure 9: The dependence of the stanit wear on the normal load. 


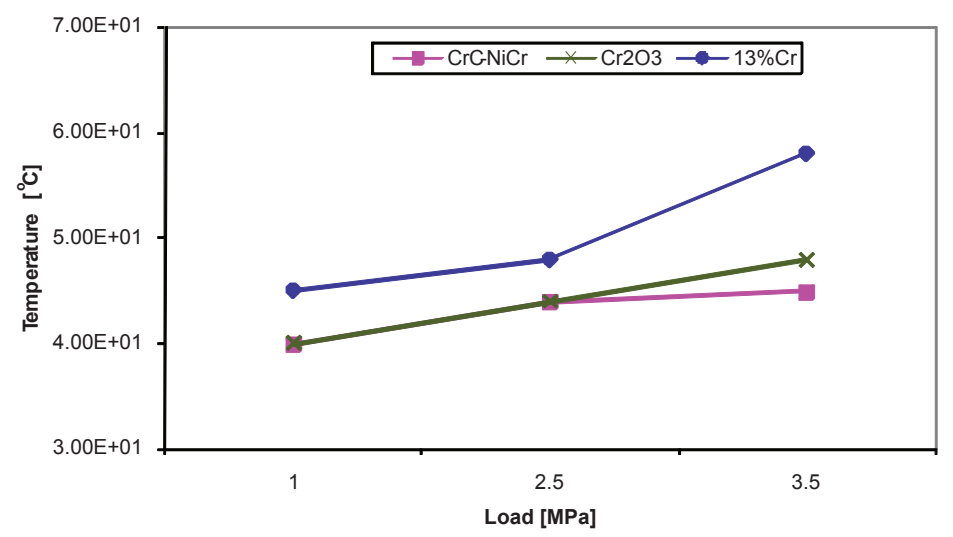

Figure 10: The dependence of the temperature on the normal load.

\section{Conclusion}

The tribological properties of three different sliding couples were evaluated. Three chosen thermally sprayed coatings $\left(\mathrm{Cr}_{3} \mathrm{C}_{2}-\mathrm{NiCr}, \mathrm{Cr}_{2} \mathrm{O}_{3}\right.$ and $13 \% \mathrm{Cr}$ stainless steel coatings) and the stanit thin-base babbitts as a counterpart were tested. The normal loads and the amount of lubricant supply were changed. The mixed friction was detected for all of chosen test parameters. Found friction properties, such as the friction force and coefficient of friction, didn't change significantly with parameters changing. The friction force was changed between the materials used only in terms of Newton and the coefficient of friction varies in narrow range (between 0.016-0.027 under the load of $1 \mathrm{MPa}$, between 0.023 0.028 under the load of $2.5 \mathrm{MPa}$ and between $0.24-0.032$ under the load of 3.5 $\mathrm{MPa})$. Therefore, the wear rate of the stanit is then the determinant parameter for evaluation of friction properties of chosen thermally sprayed coatings and stanit as the counter-part.

It was found that least convenient material for the sliding couple of coating/stanit is the $13 \% \mathrm{Cr}$ stainless steel coating that was manufactured using arc spray technology. This coating caused the highest wear of the stanit in all ranges of used normal loads, despite of its lowest hardness. Whereas, the hard plasma sprayed coating of $\mathrm{Cr}_{2} \mathrm{O}_{3}$ ceramic, that has with the stanit the lowest coefficient of friction, causes the lowest wear of the stanit and from all tested coatings proved the best friction properties with the stanit.

\section{Acknowledgement}

This paper was written thanks to the financial support of the EUREKA E!4504 Project No. OE09001. 


\section{References}

[1] Bhushan, B., Introduction to tribology, published by John Wiley and Sons, New York, pp. 207-209 and pp. 544-557, 2002

[2] Vocel, M., Dufek, V. et al., Friction and wear of machine parts, SNTL publisher of technical literature, Prague, pp. 28-30, 1976

[3] ASTM G77 - 05, Standard Test Method for Ranking Resistance of Materials to Sliding Wear Using Block-on-Ring Wear Test, ASTM International, West Conshohocken, PA, www.astm.org

[4] Matthews, S., James, B., Hzland, M., The Effect of Heat treatment on the Oxidation Mechanism of Blanded Powder $\mathrm{Cr}_{3} \mathrm{C}_{2}-\mathrm{NiCr}$ Coatings, Thermal Spray 2009: Proceedings of the International Thermal Spray Conference, Ed. by B.R. Marple and col., ASM International, pp. 1018-1023, 2009

[5] Reichenberger, W.J., Metal Prog.III., 1955

[6] Cenek, M., Jenicek, L., Neželezné kovy, ACADEMIA: Editor of CzechSlovakai Academy of Science, Prague, 1973

[7] Čáp, A., Vybrané kapitoly z neželezných kovů a jejich slitin, Editors Centre, Plzeň, 1976

[8] Kříž, A., Description of new microstructure phases and their impact on properties of stanit tin-base babbit, Proceedings of $15^{\text {th }}$ International Conference on Metallurgy and Materials, 2006

[9] Kašparová, M, Evaluation of friction properties of steel materials and of thermal sprayed coatings together with stanit tin-babbitt counterpart, internal report of ŠKODA VÝZKUM Ltd., 2006

[10] Kašparová, M, Methodology of materials friction properties measured on VRS-3 apparatus using "Block-on-Ring" method, internal report of ŠKODA VÝZKUM Ltd., 2008 